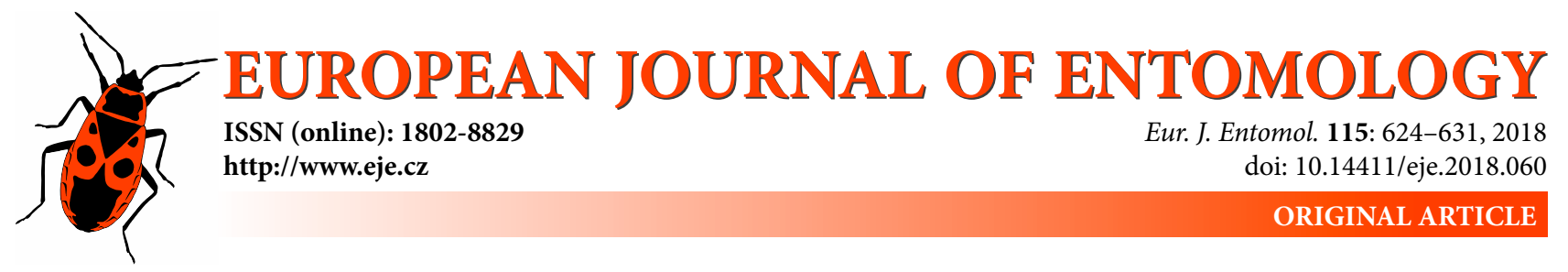

\title{
Convergent photoperiodic plasticity in developmental rate in two species of insects with widely different thermal phenotypes
}

\author{
Dmitry KUTCherov, Elena B. LOPATINA and Sergei BALAShOV \\ Department of Entomology, St. Petersburg State University, 7-9 Universitetskaya nab., St. Petersburg 199034, Russia; \\ e-mails: cyathus@yandex.ru, elena.lopatina@gmail.com, balashow@pochta.ru
}

\begin{abstract}
Key words. Hemiptera, Pyrrhocoridae, Scantius aegyptius, Coleoptera, Chrysomelidae, Timarcha tenebricosa, body size, development, photoperiod, reaction norm, seasonality, temperature

Abstract. Growth and development rates in many insects are affected by photoperiod, which enables insects to synchronize their life histories with seasonal events, but this aspect of insect photoperiodism remains understudied. Here we use several experimental combinations of constant day length and temperature to determine whether there are quantitative developmental responses to photoperiod in the bug Scantius aegyptius and leaf beetle Timarcha tenebricosa. The thermal ecology of these two species is strikingly different: the former is thermophilic and active throughout summer and the latter is spring-active and avoids the hottest time of the year. In accordance with their contrasting natural thermal environments, S. aegyptius survives better and achieves a larger final body mass at the high experimental temperatures, while $T$. tenebricosa survives better and is heavier at the low experimental temperatures. Despite this polarity, long-day conditions accelerate larval development relative to a shortday photoperiod in both species, and this developmental response is stronger at low temperatures. Our re-visitation of previous literature in light of the new findings indicates that this similarity in photoperiodic response is superficial and that relatively faster development in midsummer is likely to have a different ecological role in summer- and spring-active species. In the former, it may allow completion of an additional generation during the favourable season, whereas in the latter, this acceleration likely ensures that the larval stage, which is vulnerable to heat, is completed before the onset of hot weather.
\end{abstract}

\section{INTRODUCTION}

The lengths of night and day increase and decrease during the course of a year with the same, astronomically precise and nearly invariable pattern. This is why many organisms use photoperiod as a reliable seasonal cue and adjust their metabolism and behaviour so as to remain in synchronization with the external environment (Danilevskii, 1965; Beck, 1980; Bradshaw \& Holzapfel, 2007; Saunders, 2008; Goto \& Numata, 2014). Photoperiodic responses are diverse. Many of them are dramatic, such as seasonal migrations and dormancy, and have been extensively studied (Nelson et al., 2010). By contrast, the photoperiodic plasticity of continuously varying traits is subtle and has received limited attention. The influence of photoperiod on the rates of growth and development belongs to the latter category: despite the vast number of documented cases, no theory exists to encompass the diversity of these responses.

Evidence for the photoperiodic control of insect growth and developmental rates remained scattered in literature until a list of case studies was first compiled by Beck (1980) and then revised and substantially expanded by Danks (1987). Over the next three decades, numerous experimental studies were added that yet await compila- tion, analysis and synthesis. At first glance, the sheer variety of taxa, lifestyles, photoperiodic responses and, last but not least, experimental designs is so wide that drawing any generalizations seems challenging. Furthermore, it has long been noted that the rate-controlling effect of photoperiod may depend on other factors, especially temperature. The difference may be merely quantitative such that a particular photoperiod exerts a strong effect at one temperature and little or no effect at another (Vinogradova, 1960; Ingram \& Jenner, 1976), but sometimes there is a reversal of photoperiodic effect at high temperatures relative to that in cooler conditions, e.g., acceleration versus retardation (Geispitz et al., 1971; Goryshin \& Akhmedov, 1971; Lopatina et al., 2007). Due to the growing appreciation of the role of reaction norms in adaptive evolution (Schlichting \& Pigliucci, 1998; Murren et al., 2014; Kivelä et al., 2015), these photoperiod-temperature interactions are currently interpreted as photoperiodic plasticity of thermal reaction norms for growth and development (Gotthard et al., 1999; Lopatina et al., 2007; Kutcherov et al., 2015). However, studies on insect growth and development at several combinations of temperature and photoperiod have also produced a patchwork of examples with nearly as 
many patterns of photoperiodic plasticity as species studied (Kutcherov et al., 2011; Lopatina et al., 2011).

Despite the complications outlined above, the ability to predict the pattern of photoperiodic plasticity would be a significant improvement to the existing phenological models for economically important species. More research on insects from different thermal environments would be needed before any regularities become discernible in the diverse effects of photoperiod on growth and development. Thus, we are conducting a long-term study during which various insect species are being tested under commongarden conditions for their simultaneous responses to constant temperatures and photoperiods. This communication presents the results of our experiments with two species of insects that are adapted to contrasting thermal environments and yet turn out to have intriguingly convergent developmental responses to photoperiod in the non-stressful temperature range. We did not have any particular hypothesis regarding the response because, given the plethora of published research, virtually any kind of response could be expected a priori and backed up a posteriori. However, the similarity of the responses in these two species of insects motivated us to revisit previously published evidence, and at least some pieces of this life-history puzzle eventually fitted together, forming a ground for hypothesis-driven research in the future.

\section{MATERIALS AND METHODS}

\section{Study species}

The experiments were carried out with two taxonomically unrelated and ecologically dissimilar insect species: the true bug Scantius aegyptius (Linnaeus, 1758) (Hemiptera: Pyrrhocoridae) and the leaf beetle Timarcha tenebricosa (Fabricius, 1775) (Coleoptera: Chrysomelidae). Both these species occur in the easternmost parts of the Mediterranean region, broadly defined here as the area around the Black and Levantine Seas with a subtropical climate.

Scantius aegyptius is a flightless, soil surface-dwelling bug distributed from the Canary Islands to the Caucasus and Central Asia and recently introduced to California (Pluot, 1978; Carapezza et al., 1999; Bryant, 2009). It feeds on the seeds of Malvaceae and other plants as well as on small insects (Puchkov, 1974; Bryant, 2009; Krajicek et al., 2016). The bug spends the winter in the adult stage, hiding in crevices in soil and rock, under bark and in buildings (Puchkov, 1974). In Crimea, S. aegyptius females start egg-laying in the second half of May and the new generation adults reproduce in July (Puchkov, 1974). The species is either univoltine or bivoltine in France (Pluot, 1978) but seems to be multivoltine in northern Egypt where larvae are encountered all year round (El Shazly, 1993).

Timarcha tenebricosa is a flightless herbivorous beetle that occurs widely throughout the warmer regions in Europe, from Portugal and the shores of the English Channel to the southeast of the European part of Russia (Bechyně, 1945; Kuzovenko et al., 2015). Larvae and adults feed openly on the leaves and stems of Galium spp. (Jolivet \& Petitpierre, 1973). The life cycle of T. tenebricosa is somewhat complicated and involves obligatory embryonic diapause and two types of facultative imaginal diapause (in summer and autumn). The following short account is based on the extensive observations and experiments of Jolivet (1972) and Chevin $(1985,1994)$ in France and those of Cox (1994) in
Great Britain. Beetles mate from spring to autumn, and females lay eggs in soil. In some populations, continuous reproduction is interrupted by summer aestivation. Embryogenesis proceeds until the larva is formed, which spends the winter in obligatory diapause inside the eggshell and hatches early in spring. Larvae pass through three instars, pupate in soil, and adults emerge the same year. The earliest of the new generation of beetles can reproduce before overwintering but mating and oviposition are subsequently suppressed by short-day photoperiods and low temperatures in autumn. Adults that emerge later in the season experience diapause-inducing conditions from the start and delay reproduction until the following spring. Beetles overwinter under various shelters and in soil. Thus, the whole life cycle from egg to egg lasts between one and two years.

\section{Collection and maintenance of parental individuals}

Larvae and adults of S. aegyptius were collected in mid-August 2013 in Protaras, Cyprus $\left(35^{\circ} 1^{\prime} \mathrm{N}, 34^{\circ} 1^{\prime} \mathrm{E}\right)$ and in early November 2013 in Tel Aviv, Israel $\left(32^{\circ} 4^{\prime} \mathrm{N}, 34^{\circ} 50^{\prime} \mathrm{E}\right)$. The bugs (about 20 individuals from each population) were transported by air to St. Petersburg, Russia, where they were maintained in the laboratory in half-liter plastic containers with a paper lined bottom and pieces of accordion-folded paper as shelter. The bugs were supplied with food (fruit of hollyhock Alcea rosea and linden Tilia platyphyllos) and water (Eppendorf tubes filled with water and plugged with cotton wool), which were replenished as needed. The containers were kept in an environmental chamber at a temperature of $25^{\circ} \mathrm{C}$ and under a $12 \mathrm{~L}: 12 \mathrm{D}$ photoperiod. The larvae and adults were allowed to complete development and accumulate reserves for overwintering. Then the rearing temperature was gradually decreased, and the bugs were transferred to a cool room with a temperature of $4^{\circ} \mathrm{C}$ where they were stored until late January 2014 when the experiment began.

Three males and six females of T. tenebricosa were collected on the 26th and 28th of April 2016 in the oak forest understory on the southern slope of Demirci Mountain in Crimea $\left(44^{\circ} 31^{\prime} \mathrm{N}\right.$, $\left.34^{\circ} 9^{\prime} \mathrm{E}\right)$. The insects were transported by air to the laboratory in St. Petersburg and kept throughout the summer in two 1-liter plastic containers with fresh bedstraw Galium mollugo on top of a 1-cm layer of moistened sawdust. Dead tree twigs were also put in the containers to prevent the bedstraw from compacting and to increase the space available to beetles. The containers were kept in an environmental chamber where temperature fluctuated between 20 and $24^{\circ} \mathrm{C}$ and photoperiod was first increased from 15L:9D in May to 16L: 8D in June and then gradually decreased over the period July to August to $12 \mathrm{~L}: 12 \mathrm{D}$ in September. The sawdust was checked daily for the presence of newly laid eggs and the bedstraw was changed as necessary. Groups of 3-10 eggs collected on the same day were transferred into $4 \mathrm{~cm}^{3}$ plastic cups filled with moist sawdust and incubated in darkness at $17^{\circ} \mathrm{C}$ for 55 days, after which they were passed through a series of decreasing temperatures and then kept in a cool room at $4{ }^{\circ} \mathrm{C}$ until late January 2017 when the experiment was started. In total, the six females laid 511 eggs, 318 of which hatched after the simulated overwintering.

\section{Experimental procedures}

Pairs of overwintered S. aegyptius (a female and a male) were kept in plastic Petri dishes (60 $\mathrm{mm}$ in diameter) in an environmental chamber at $22^{\circ} \mathrm{C}$ under a long-day photoperiod of 16L: 8D. Bugs were fed with fruit of hollyhock and linden. Water was provided in Eppendorf tubes stoppered with a cotton wool plug. Eggs were collected daily and transferred to small plastic Petri dishes (40 $\mathrm{mm}$ in diameter) which were kept in larger dishes (100 $\mathrm{mm}$ in diameter) on a layer of damp cotton wool to pre- 
vent desiccation. Clutches, comprised of from 6 to 52 eggs, were mixed to minimize possible noise created by interfamilial variation. Groups of 15 to 20 eggs derived from this common pool were then randomized among ten experimental regimens: five constant temperatures $\left(20,22,24,26\right.$ and $\left.28^{\circ} \mathrm{C}\right)$ and two photoperiods (short-day 10L: $14 \mathrm{D}$ and long-day $16 \mathrm{~L}: 8 \mathrm{D}$ ), one chamber per treatment. Hatching was recorded daily. As hatchlings in each group emerged synchronously, all eggs that remained after mass emergence were considered non-viable. Larvae were transferred to $90 \mathrm{~mm}$ Petri dishes on the day of hatching and to $250 \mathrm{ml}$ containers after moulting to the third instar. Larvae were supplied with food and water in the same manner as the adults. Newly emerged adults were recorded daily and weighed using the Gosmetr VL-210 digital analytical balance with $0.1 \mathrm{mg}$ precision.

Post diapause eggs of T. tenebricosa were monitored daily, and on the day of hatching each larva was randomly allocated to one of eight experimental regimens: four temperatures $(14,18,22$ and $26^{\circ} \mathrm{C}$ ) and two photoperiods (short-day $12 \mathrm{~L}: 12 \mathrm{D}$ and long-day $16 \mathrm{~L}: 8 \mathrm{D})$. Larvae were kept individually in $4 \mathrm{~cm}^{3}$ plastic cups with ventilation holes in the plug and a layer of coconut substrate, which served both as a source of moisture and a substitute for soil. Soon after moulting to the third (final) instar, each larva was transferred to a $250 \mathrm{ml}$ container, also with a coconut substrate on the bottom. Larvae were fed ad libitum with freshly cut indoorgrown G. mollugo until they dug into the substrate and built a pupation chamber. Prepupae and pupae were monitored daily, and interstadial moults were recorded. Adults were weighed on an Ohaus electronic balance $(0.01 \mathrm{mg}$ precision) the day after eclosion when their integument had hardened.

Temperature in the environmental chambers was maintained at $\pm 0.1-0.5^{\circ} \mathrm{C}$ using a software-controlled balance of heating and cooling (RLDataView 1.03; Research Laboratory of Design Automation, Taganrog, Russia) and was automatically recorded every $10 \mathrm{~s}$. Actual rearing temperatures deviated slightly from the set values and are given in Tables 1 and 2. The chosen long-day photoperiod of $16 \mathrm{~L}: 8 \mathrm{D}$ approximately corresponds to midsummer day length (including civil twilight) at the collection sites, whereas the short-day photoperiod for $S$. aegyptius had a shorter photophase than that for T. tenebricosa because the former species experiences a broader range of day lengths in nature.

Table 1. Mean ( \pm SD) duration (days) of immature stages of Scantius aegyptius under five constant temperatures and two photoperiods.

\begin{tabular}{|c|c|c|c|c|c|c|c|}
\hline \multicolumn{2}{|c|}{$\begin{array}{c}\text { Temperature } \\
\left({ }^{\circ} \mathrm{C}\right)\end{array}$} & \multirow{2}{*}{$\begin{array}{c}\text { Day } \\
\text { ength (h) }\end{array}$} & \multirow[t]{2}{*}{ Eggs } & \multirow[t]{2}{*}{$n^{\dagger}$} & \multirow[t]{2}{*}{$n^{\ddagger}$} & \multirow[t]{2}{*}{ Larvae } & \multirow[t]{2}{*}{$n^{\ddagger}$} \\
\hline Set & Real & & & & & & \\
\hline \multirow{2}{*}{20} & 20.3 & 10 & $16.8 \pm 1.73$ & 8 & 124 & - & 0 \\
\hline & 20.1 & 16 & $15.2 \pm 0.74$ & 7 & 121 & - & 0 \\
\hline \multirow{2}{*}{22} & 22.1 & 10 & $12.1 \pm 1.88$ & 8 & 109 & $51.3 \pm 2.16$ & 41 \\
\hline & 22.1 & 16 & $12.1 \pm 0.75$ & 8 & 123 & $47.7 \pm 2.03$ & 61 \\
\hline \multirow{2}{*}{24} & 24.1 & 10 & $8.0 \pm 1.36$ & 4 & 54 & $35.8 \pm 0.72$ & 48 \\
\hline & 23.8 & 16 & $8.1 \pm 0.12$ & 5 & 83 & $33.4 \pm 2.07$ & 70 \\
\hline \multirow{2}{*}{26} & 26.1 & 10 & $7.0 \pm 0.79$ & 6 & 136 & $27.9 \pm 1.79$ & 103 \\
\hline & 26.5 & 16 & $7.1 \pm 0.48$ & 6 & 109 & $24.8 \pm 1.32$ & 98 \\
\hline \multirow{2}{*}{28} & 27.8 & 10 & $5.9 \pm 0.18$ & 4 & 69 & $22.7 \pm 1.47$ & 47 \\
\hline & 27.6 & 16 & $5.8 \pm 0.34$ & 7 & 97 & $23.1 \pm 1.15$ & 87 \\
\hline \multicolumn{8}{|c|}{ ANCOVA results: } \\
\hline \multicolumn{3}{|c|}{ Temperature } & \multicolumn{2}{|c|}{$\begin{array}{l}F_{1,59}=664 \\
P<0.0001\end{array}$} & & \multicolumn{2}{|c|}{$\begin{array}{c}F_{1,552}=8018 \\
P<0.0001\end{array}$} \\
\hline \multicolumn{3}{|c|}{ Photoperiod } & \multicolumn{2}{|c|}{$\begin{array}{c}F_{1,59}=2 \\
P=0.2\end{array}$} & & \multicolumn{2}{|c|}{$\begin{array}{l}F_{1,552}=94 \\
P<0.0001\end{array}$} \\
\hline
\end{tabular}

${ }^{\dagger}$ Number of clutches (proper replicates for the egg stage). ‡Number of individuals (egg and larval sample sizes differ because of mortality).

\section{Statistical analyses}

In all analyses, temperature was treated as a continuous predictor and photoperiod as a categorical predictor. The influence of temperature and photoperiod on survivorship was tested using generalized linear models (GLM) with a logit link and binomial error structure. For illustration purposes, survival rates were expressed as a percentage of individuals successfully completing a given stage \pm binomial SE.

The duration $(D)$ of each immature stage (eggs and larvae in $S$. aegyptius; larvae and pupae in T. tenebricosa) was transformed into a rate $(R=1 / D)$, and temperature-dependent development was described assuming a linear regression between the mean rate of development $(R)$ and temperature $(T): R=a+b T$ (Campbell et al., 1974). The sum of degree-days (SDD) was calculated as $1 / b$, and the lower temperature threshold (LTT) as $-a / b$. The standard error of the slope (coefficient $b$ ) was estimated according to Sokal \& Rohlf (1995: pp. 484-485). The standard error of the LTT was obtained from the approximate formula proposed by Campbell et al. (1974).

A preliminary inspection of developmental data showed that, similarly to developmental rate, body mass also changed monotonically with temperature, and so the simultaneous effect of temperature and photoperiod on these traits was tested using ANCOVA with a prior test for equality of slopes. To improve homogeneity of variances and normality of residuals, individual values of developmental rate (multiplied by 100) and adult body mass were natural log-transformed. Data obtained for S. aegyptius from Cyprus and Israel were pooled because there were no significant differences in the responses to temperature and photoperiod between these two populations. Statistical procedures were conducted in Statistica 7.1 (C StatSoft, Inc., 1984-2006, Tulsa, OK, USA).

\section{RESULTS}

\section{Survivorship}

Eggs of the bug $S$. aegyptius had similar hatchability between 20 and $28^{\circ} \mathrm{C}$ under both photoperiodic regimens (temperature: Wald's $\chi_{1,1620}^{2}=0.01$; photoperiod: Wald's $\chi_{1,1620}^{2}=1.1 ; P>0.2$ for both factors) (Fig. 1A). In contrast, larval survivorship in $S$. aegyptius was significantly affected by both temperature (Wald's $\chi_{1,1025}^{2}=281.4, P<0.0001$ )

Table 2. Mean ( \pm SD) duration (days) of immature stages of Timarcha tenebricosa under four constant temperatures and two photoperiods.

\begin{tabular}{|c|c|c|c|c|c|c|}
\hline \multicolumn{2}{|c|}{$\begin{array}{c}\text { Temperature } \\
\left({ }^{\circ} \mathrm{C}\right)\end{array}$} & \multirow{2}{*}{$\begin{array}{c}\text { Day } \\
\text { length }(h)\end{array}$} & \multirow[t]{2}{*}{ Larvae } & \multirow[t]{2}{*}{$n^{\dagger}$} & \multirow[t]{2}{*}{ Pupae } & \multirow[t]{2}{*}{$n^{\dagger}$} \\
\hline Set & Real & & & & & \\
\hline \multirow{2}{*}{14} & 14.1 & 12 & $105.9 \pm 8.65$ & 10 & $36.2 \pm 0.56$ & 2 \\
\hline & 14.2 & 16 & $89.3 \pm 5.30$ & 12 & $36.2 \pm 0.50$ & 4 \\
\hline \multirow{2}{*}{18} & 17.9 & 12 & $72.0 \pm 5.34$ & 9 & $23.9 \pm 0.62$ & 4 \\
\hline & 17.8 & 16 & $66.8 \pm 9.67$ & 17 & $23.6 \pm 1.14$ & 8 \\
\hline \multirow{2}{*}{22} & 21.9 & 12 & $54.3 \pm 6.20$ & 14 & $17.5 \pm 0.49$ & 4 \\
\hline & 22.0 & 16 & $45.1 \pm 3.20$ & 14 & $17.0 \pm 0.57$ & 9 \\
\hline \multirow{2}{*}{26} & 26.1 & 12 & $41.1 \pm 3.63$ & 3 & - & 0 \\
\hline & 26.0 & 16 & $39.2 \pm 7.03$ & 3 & - & 0 \\
\hline \multicolumn{7}{|c|}{ ANCOVA results: } \\
\hline \multicolumn{3}{|c|}{ Temperature } & \multicolumn{2}{|l|}{$\begin{array}{l}F_{1,79}=606 \\
P<0.0001\end{array}$} & \multicolumn{2}{|c|}{$\begin{array}{c}F_{1,28}=1129 \\
P<0.0001\end{array}$} \\
\hline \multicolumn{3}{|c|}{ Photoperiod } & $\begin{array}{c}F_{1,79}=34, \\
P<0.0001\end{array}$ & & \multicolumn{2}{|l|}{$\begin{array}{c}F_{1,28}=0.6 \\
P=0.5\end{array}$} \\
\hline
\end{tabular}

†Number of individuals (larval and pupal sample sizes differ because of mortality). 


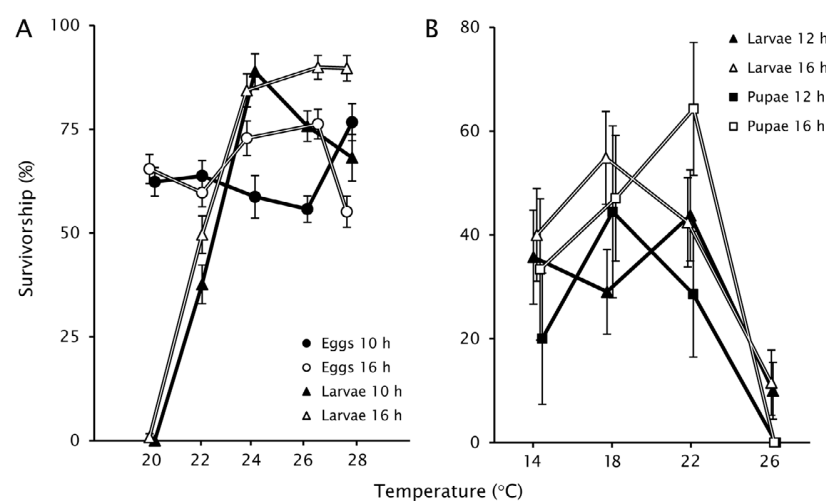

Fig. 1. Survivorship of immature stages of (A) S. aegyptius and (B) $T$. tenebricosa at different combinations of temperature and photoperiod. Symbols are slightly set apart along the temperature axis for clarity. Vertical bars denote binomial SE.

and photoperiod (Wald's $\chi_{1,1025}^{2}=16.8, P<0.0001$ ). Bug larvae survived better at temperatures above $22^{\circ} \mathrm{C}$, especially combined with long-day conditions (Fig. 1A), and the only adult that emerged at $20^{\circ} \mathrm{C}$ (one from the Cyprus population) did so also under the day length of $16 \mathrm{~h}$.

In T. tenebricosa, temperature and photoperiod influenced larval survival in a fashion that broadly recurred in pupae (Fig. 1B). There was a significant effect of temperature on the postembryonic survivorship (from hatching to adult eclosion, Wald's $\chi_{1,241}^{2}=7.5, P<0.01$ ), such that both stages suffered the greatest mortality at the highest experimental temperature of $26^{\circ} \mathrm{C}$ and fared better at the three lower temperatures (Fig. 1B). Similar to larvae of $S$. aegyptius, larvae and pupae of the leaf beetle showed significantly better survival under long-day conditions (from hatching to eclosion: Wald's $\chi_{1,241}^{2}=4.3, P<0.05$ ) (Fig. 1B).

\section{Immature development}

Temperature had a significant effect on the development of S. aegyptius eggs and larvae (Table 1) and T. tenebrico$s a$ larvae and pupae (Table 2), as expected for ectothermic organisms. Temperature-dependent developmental rates were well approximated by straight lines over the temperature range studied (Table 3; Fig. 2) with all $r^{2}$ values exceeding 0.98 . Photoperiod did not influence the slope of the temperature-rate relationship in either species ( $S$. aegyptius eggs: $F_{1,59}=1.8, P>0.1 ; S$. aegyptius larvae: $F_{1,547}$ $=5.3, P>0.02 ;$ T. tenebricosa larvae: $F_{1,78}=0.05, P>$ 0.8; T. tenebricosa pupae: $F_{1,27}=0.6, P>0.4$; slope and intercept values are in Table 3 ). Egg development rate in

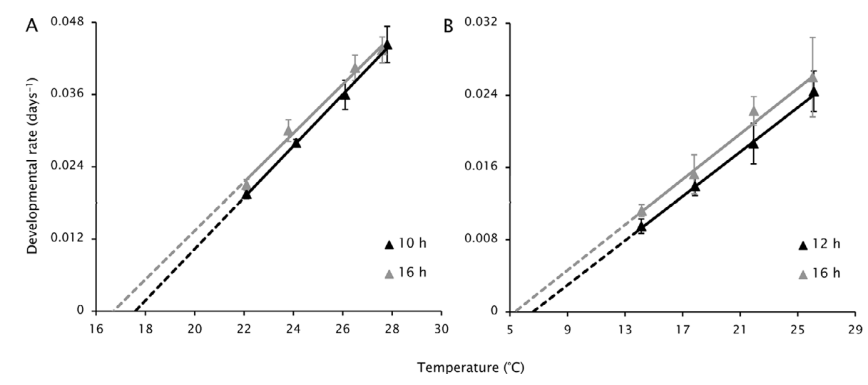

Fig. 2. Linear thermal reaction norms based on the larval development of (A) S. aegyptius and (B) T. tenebricosa recorded under short-day (10 h or $12 \mathrm{~h}$ ) and long-day (16 h) photoperiodic conditions. Symbols with bars refer to mean developmental rates \pm SD; their position on the temperature axis matches actual temperatures during the experiments.

S. aegyptius and pupal development rate in T. tenebricosa were unaffected by photoperiod, but larvae of both species developed significantly faster under long-day conditions, especially so at lower temperatures (Tables 1 and 2).

\section{Adult body mass}

Temperature $\left(F_{1.552}=910, P<0.0001\right)$ and photoperiod $\left(F_{1,552}=32, P<0.0001\right)$ during immature development significantly influenced adult body mass in $S$. aegyptius. The bugs were heavier at higher temperatures, and shortday individuals were generally heavier than their long-day counterparts (Fig. 3A). The slope of the temperature-mass relationship was unaffected by photoperiod (temperature by photoperiod interaction: $\left.F_{1.547}=0.03, P>0.9\right)$ and was estimated at $0.098 \pm 0.005$ and $0.099 \pm 0.004( \pm$ SE) under short-day and long-day conditions, respectively. The effect of temperature on T. tenebricosa body mass was marginally significant $\left(F_{1,27}=910, P=0.03\right)$ and opposite to that in $S$. aegyptius (slope \pm SE: $-0.015 \pm 0.006$ ), while the effect of photoperiod was not significant $\left(F_{1,27}=0.7, P>0.4\right)$, likely because of small sample sizes. However, it is still worth noting that, unlike S. aegyptius, T. tenebricosa adults from long-day conditions were on average heavier than those from the short-day photoperiodic regimen (Fig. 3B).

\section{DISCUSSION}

The pyrrhocorid bug S. aegyptius and the leaf beetle $T$. tenebricosa have markedly divergent thermal phenotypes that likely reflect adaptation to different thermal environments. Our results suggest that $S$. aegyptius can be designated as a warm-adapted species, as the larvae survive better at temperatures of $22^{\circ} \mathrm{C}$ and higher (Fig. 1A), the lower

Table 3. Linear regression parameters $( \pm$ SE) for temperature-dependent development in S. aegyptius and T. tenebricosa.

\begin{tabular}{cccccc}
\hline $\begin{array}{c}\text { Species and } \\
\text { developmental stage }\end{array}$ & Day length & $a\left(\right.$ day $\left.^{-1}\right)$ & $b\left({ }^{\circ} \mathrm{C}^{-1} \times\right.$ day $\left.{ }^{-1}\right)$ & $\begin{array}{c}\text { Lower temperature } \\
\text { threshold }\left({ }^{\circ} \mathrm{C}\right)\end{array}$ & $\begin{array}{c}\text { Sum of degree-days } \\
\left({ }^{\circ} \mathrm{C} \times \text { day }\right)\end{array}$ \\
\hline S. aegyptius eggs & $-{ }^{\dagger}$ & -0.2272 & $0.0143 \pm 0.00121$ & $15.9 \pm 1.54$ & $70.0 \pm 5.94$ \\
S. aegyptius larvae & 10 & -0.0752 & $0.0043 \pm 0.00013$ & $17.6 \pm 1.26$ & $233.7 \pm 7.12$ \\
& 16 & -0.0677 & $0.0041 \pm 0.00029$ & $16.7 \pm 1.40$ & $246.8 \pm 17.83$ \\
T. tenebricosa larvae & 12 & -0.0081 & $0.0012 \pm 0.00005$ & $6.6 \pm 2.63$ & $813.2 \pm 29.80$ \\
T. tenebricosa pupae & 16 & -0.0067 & $0.0013 \pm 0.00012$ & $5.3 \pm 2.97$ & $794.0 \pm 78.03$ \\
\hline
\end{tabular}

${ }^{\dagger}$ Data from two photoperiodic regimens combined. 


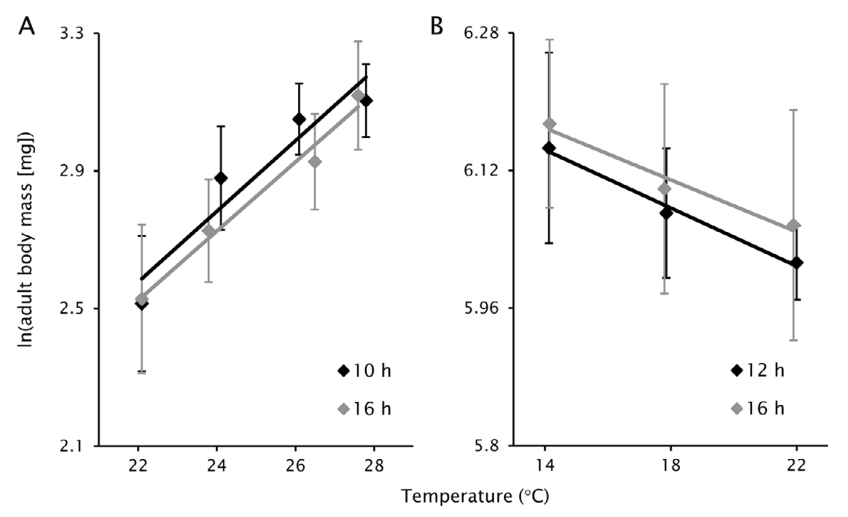

Fig. 3. Adult body size (natural log-transformed) in (A) S. aegyptius and (B) T. tenebricosa after rearing at different combinations of temperature and photoperiod. Symbols with bars refer to body mass values $\pm S D$; their position on the temperature axis matches actual temperatures during the experiments.

thresholds for immature development range from 15.9 to $17.6^{\circ} \mathrm{C}$ (Fig. 2A, Table 3 ) and a larger body mass is attained at higher temperatures (Fig. 3A). By contrast, T. tenebricosa survives better at temperatures of $22^{\circ} \mathrm{C}$ and cooler (Fig. 1B), its lower thresholds for development range from 5.3 to $7.3^{\circ} \mathrm{C}$ (Fig. 2B, Table 3 ) and adult body mass increases with decreasing developmental temperature (Fig. 3B). In spite of all these differences, the photoperiodic plasticity of larval developmental rate is essentially identical, i.e., in both species long-day photoperiod accelerates larval development over the whole temperature range studied (Fig. 2). Differences in the slopes of the thermal reaction norms between photoperiods are minor, indicating a disproportional effect on developmental rates. In fact, the developmental response to long-day conditions is stronger at the lowest experimental temperature in both species (7.0 and $15.7 \%$ acceleration in $S$. aegyptius and T. tenebricosa, respectively) than it is at the highest temperature $(-1.9 \%$ and $4.6 \%$, respectively; note that the response is slightly reversed in the former species). Also, the photoperiodic control of body mass in S. aegyptius and T. tenebricosa seem to have opposite patterns (Fig. 3), but statistical support for this conclusion is limited.

The main question is whether S. aegyptius and T. tenebricosa, two species from the easternmost parts of the Mediterranean region, have evolved this photoperiodic developmental plasticity in response to the same seasonal constraint. In other words, does the long-day acceleration of larval development in S. aegyptius play the same ecological role as it does in T. tenebricosa?

Acceleration of development and/or growth by long-day photoperiods seems to be the prevalent pattern as it occurs in almost two thirds of cases (58 out of 92) listed in Beck (1980) and Danks (1987). It remains to be clarified, however, whether this is a long-day acceleration or short-day retardation. As both fast and slow development may incur fitness costs (Fordyce \& Shapiro, 2003; Dmitriew, 2011), discussing photoperiodic effects in terms of acceleration and retardation naturally raises the question of whether insects ever develop at a balanced rate, without speeding up or slowing down. A closer look at these 58 cases reveals that relatively slow larval development caused by shortday conditions is usually immediately followed by larval diapause (either obligatory or induced by the same photoperiod - 32 cases in total) or larval quiescence (further nine cases). Another five cases are moth caterpillars that enter short-day or obligatory diapause as pupae and may already be committed to diapause in the larval stage. Evidence for the presence of diapause or quiescence in these insects is quite often provided by the authors of these studies; alternatively, this topic is at least briefly discussed, and further information can be found in referenced works. What remains is just 12 cases where long-day conditions accelerate active larval development, i.e., development that would otherwise proceed without a notable interruption, only at a slower pace.

Thus, if a short-day photoperiod slows down immature development and this is followed by a full developmental arrest (diapause), as is often the case, it seems inappropriate to say that a long-day photoperiod accelerates development because it is exactly under long-day conditions that unhurried, yet uninhibited, development takes place. Such quantitative photoperiodic effects on developmental rate may be difficult to disentangle from qualitative responses (i.e., diapause) because there are problematic intermediate states between active development and diapause and numerous forms of diapause itself which are notoriously difficult to categorize (Danks, 1987). However, distinction must be made between different kinds of photoperiodically induced "acceleration" in order to avoid combining unrelated phenomena.

True long-day acceleration of development, which is not causally linked to short-day induction of diapause, is therefore rather uncommon, perhaps in part owing to the fact that most insects studied in terms of photoperiodism come from relatively high latitudes. As far as we are aware, examples of long-day acceleration of insect development that have been discovered so far include (but most certainly are not limited to) the following.

In the experiments carried out at a single temperature, long-day photoperiods accelerate larval development in a number of true bugs and other insects from the Mediterranean region and other relatively warm climates (Zohdy \& Abou-Elela, 1975; El-Helaly et al., 1977; Abdel-Malek et al., 1982; He, 2000; Ishihara, 2000; Mansfield et al., 2007; Bahşi \& Tunç, 2008; Wang et al., 2013; Zerbino et al., 2014; Pazyuk \& Reznik, 2016). It is worth noting, however, that all of the populations studied are multivoltine or at least bivoltine. Some of these insects can even develop without diapause all year round and are widespread serious pests in the tropics, namely, the cowpea aphid Aphis craccivora (Abdel-Malek et al., 1982), Egyptian cottonworm Spodoptera littoralis (Zohdy \& Abou-Elela, 1975) and silverleaf whitefly Bemisia tabaci (El-Helaly et al., 1977).

Studies that involve several combinations of temperature and photoperiod are more informative and reveal a greater diversity of responses. Two multivoltine species from Egypt, the bug Nezara viridula (Ali \& Ewiess, 1977) and 
the lady beetle Epilachna chrysomelina (Ali \& El-Saeady, 1981), develop faster under long-day than under short-day conditions at all the temperatures tested. This quantitative photoperiodic response in $N$. viridula is especially similar to that in S. aegyptius because the influence of photoperiod is also more pronounced at lower temperatures, whereas in E. chrysomelina, the long-day acceleration is more or less proportional over the temperature range studied.

The green lacewing Chrysopa pallens, which is trivoltine in the temperate zone of European Russia, also exhibits long-day acceleration over the whole temperature range studied, while the partially bivoltine $C$. phyllochroma shows a weaker but essentially the same photoperiodic response (Blumental, 1996; Volkovich \& Orlova, 1998). Again, the photoperiodic effect is relatively stronger at lower temperatures.

May the emerging link between voltinism and long-day acceleration of development be merely a coincidence? Studies of different populations of the same species are particularly helpful in this regard. In the cricket Dianemobius fascipes, larval development at $27^{\circ} \mathrm{C}$ (the only temperature tested) is accelerated by short-day photoperiods in northern univoltine populations and by both short- and long-day (as opposed to intermediate) photoperiods in southern bivoltine populations (Masaki, 1972). The northern, partially bivoltine population of the bug Dolycoris baccarum exhibits slightly faster development under short-day conditions, in contrast to the southern trivoltine population where the long-day photoperiod accelerates larval development at all the temperatures tested (Nakamura, 2003). Finally, northern populations of the firebug Pyrrhocoris apterus exhibit long-day acceleration of development at high, but not low, temperatures because of a strong temperature-photoperiod interaction, whereas in the southern population, a long-day photoperiod accelerates development at all temperatures but one (Lopatina et al., 2007).

Thus, long-day acceleration of immature development is more pronounced in populations from warmer climates and seems to facilitate the completion of additional generations during summer in potentially multivoltine species, including $S$. aegyptius. This explanation is irrelevant to T. tenebricosa, as its life cycle takes one year, at the very least. There are, however, a few examples of long-day acceleration in insects with similar seasonal activity.

Larval development of the noctuid moth Phlogophora meticulosa in France takes place during winter and spring and its rate of development is faster under long-day conditions over the whole favourable temperature range, which is remarkably similar to that in T. tenebricosa: the lower temperature threshold of $5^{\circ} \mathrm{C}$ and almost $100 \%$ mortality at $25^{\circ} \mathrm{C}$ (Bues \& Poitout, 1980). In a similar vein, immature stages of the winter-active rove beetle Quedius pellax from the Pacific coast of North America have lower temperature thresholds around zero and die at $20^{\circ} \mathrm{C}$, while larval development is also faster under a long-day photoperiod (Topp \& Smetana, 1998). Besides, long-day acceleration of development is observed at all temperatures tested in post diapause larvae of Odonata (Shepard \& Lutz, 1976;
Norling, 1984,) and Lepidoptera (Sugiki \& Masaki, 1972; Gotthard et al., 1999, 2000), which resume development in early spring.

Thus, even though the photoperiodic responses during immature development are superficially similar in $S$. $a e-$ gyptius and T. tenebricosa, their ecological roles seem to be different. In the former species, relatively faster development under long-day conditions seems to be advantageous because it will ensure the completion of an additional generation in summer. By contrast, in winter- and springactive species, such as $T$. tenebricosa, this reaction may help to avoid unfavourably high summer temperatures. A feature common to both cases is that long-day acceleration of immature development eventually reduces heterogeneity in adult emergence times.

It is also worth noting that the quantitative photoperiodic response can be disproportionately stronger at lower or higher temperatures, which is true of both the species studied by us and the majority of previously published cases. Although, for the sake of simplicity, we have only discussed a change in absolute developmental rate (acceleration) as the most apparent response, it should be borne in mind that photoperiod often changes the degree of thermal plasticity of developmental rate, which may have an adaptive value of its own.

ACKNOWLEDGEMENTS. The authors are grateful to M. Ryzhkova, K. Bukatina and I. Gusev who helped with rearing the experimental insects. S.B. is indebted to T. Novoselsky and A.L.L. Friedman (Zoological Museum, Department of Zoology, Tel Aviv University) for their help in arranging the travel to Israel and in collecting $S$. aegyptius. We also thank anonymous reviewers whose critique helped to improve the manuscript. The study was supported by the Russian Foundation for Basic Research (grant no. 16-34-00534-mol_a and 14-04-01156-a) and Saint Petersburg State University (project no. 1.40.503.2017).

\section{REFERENCES}

Abdel-MaleK A., Dimetry N.Z., El-Ziady S. \& El-Hawwary F.M. 1982: Ecological studies on Aphis craccivora Koch. III. The role of day length as an environmental factor regulating development and form produced. - Z. Angew. Entomol. 93: 238-243.

Ali M.A. \& EL-SAEADY A.A. 1981: Influence of temperature, photoperiod and host-plant on the bionomics of the melon ladybird Epilachna chrysomelina (F.) (Coleoptera: Coccinellidae). - Z. Angew. Entomol. 91: 256-262.

Ali M. \& EwIESs M.A. 1977: Photoperiodic and temperature effects on rate of development and diapause in the green stink bug, Nezara viridula L. (Heteroptera: Pentatomidae). $-Z$. Angew. Entomol. 84: 256-264.

BAHȘ Ş.Ü. \& Tunç İ. 2008: Development, survival and reproduction of Orius niger (Hemiptera: Anthocoridae) under different photoperiod and temperature regimes. - Biocontr. Sci. Tech. 18: 767-778.

BECHYNĚ J. 1945: De specibus generis Timarcha Latr. sectionis T. tenebricosa F. (Col. Phytoph. Chrysomelidae). — Entomol. Listy 8: 5-10.

BEcK S.D. 1980: Insect Photoperiodism, 2nd ed. Academic Press, New York, NY, 387 pp.

Blumental N.A. 1996: Photothermic Regulation of Diapause and Development in two Species of Green Lacewings: Chryso- 
pa abbreviata Curt. and Chrysopa septempunctata Wesm. (Neuroptera, Chrysopidae). MSc thesis, Saint Petersburg State University, 39 pp. [in Russian].

Bradshaw W.E. \& Holzapfel C.M. 2007: Evolution of animal photoperiodism. - Annu. Rev. Ecol. Evol. Syst. 38: 1-25.

Bryant P.J. 2009: Invasion of Southern California by the Palearctic pyrrhocorid Scantius aegyptius (Hemiptera: Heteroptera: Pyrrhocoridae). - Pan-Pac. Entomol. 85: 190-193.

Bues R. \& Poitout S. 1980: Study of the larval and pupal development of Phlogophora meticulosa L. (Lep. Noctuidae) under different controlled combinations of temperature and photoperiod. - Acta Oecol., Oecol. Appl. 1: 127-138.

Campbell A., Frazer B.D., Gilbert N., Gutierrez A.P. \& MaCKAUER M. 1974: Temperature requirements of some aphids and their parasites. - J. Appl. Ecol. 11: 431-438.

Carapezza A., Kerzhner I.M. \& Rieger C. 1999: On the subspecies of Scantius aegyptius (Linnaeus) (Heteroptera: Pyrrhocoridae). - Zoosyst. Rossica 8: 129-131 [in Russian].

Chevin H. 1985: Contribution à la biologie des Timarcha (Col. Chrysomelidae). II. Timarcha tenebricosa F. - Cah. Liaison Office Eco-Entomol. 19: 7-14.

Chevin H. 1994: Food selection and life-cycle of the Old World Timarcha Latreille, 1829 (Col. Chrysomelinae). In Jolivet P.H., Cox M.L. \& Petitpierre E. (eds): Novel Aspects of the Biology of Chrysomelidae. Springer Science+Business Media, Dordrecht, pp. 533-539.

Cox M.L. 1994: Diapause in the Chrysomelidae. In Jolivet P.H., Cox M.L. \& Petitpierre E. (eds): Novel Aspects of the Biology of Chrysomelidae. Springer Science+Business Media, Dordrecht, pp. 469-502.

DanILEVSKII A. 1965: Photoperiodism and Seasonal Development of Insects. Oliver and Boyd, Edinburgh, 283 pp.

Danks H.V. 1987: Insect Dormancy: An Ecological Perspective. Biological Survey of Canada (Terrestrial Arthropods), Ottawa, $432 \mathrm{pp}$.

DMitRIEw C.M. 2011: The evolution of growth trajectories: what limits growth rate? - Biol. Rev. 86: 97-116.

El-Helaly M.S., Ibrahim E.G. \& Rawash I.A. 1977: Photoperiodism of the whitefly Bemisia tabaci Gennadius (Aleyrodidae; Homoptera). - Z. Angew. Entomol. 83: 393-397.

El Shazly M.M. 1993: Preliminary studies on the seasonal occurrence and biology of Scantius aegyptius (L.) (Hemiptera, Heteroptera: Pyrrhocoridae) in Egypt. - Bull. Entomol. Soc. Egypt 71: 131-138.

FordyCE J.A. \& ShapiRo A.M. 2003: Another perspective on the slow-growth/high-mortality hypothesis: chilling effects on swallowtail larvae. - Ecology 84: 263-268.

Geispitz K.F., Penjas M.I. \& Shashenkova D.C. 1971: Photoperiod and temperature as developmental factors for Agrotis segetum (Lepidoptera, Noctuidea). - Zool. Zh. 50: 1674-1685 [in Russian].

Goryshin N.I. \& Akhmedov R.M. 1971: Photoperiod and temperature as factors of development of Agrotis ypsilon (Lepidoptera, Noctuidae). - Zool. Zh. 50: 56-66 [in Russian].

Goto S.G. \& Numata H. 2014: Insect photoperiodism. In Hoffmann K.H. (ed.): Insect Molecular Biology and Ecology. CRC Press, Boca Raton, pp. 217-244.

Gotthard K., Nylin S. \& WikLund C. 1999: Seasonal plasticity in two satyrine butterflies: state-dependent decision making in relation to daylength. - Oikos 84: 453-462.

Gotthard K., Nylin S. \& WikLund C. 2000: Individual state controls temperature dependence in a butterfly (Lasiommata maera). — Proc. R. Soc. (B) 267: 589-593.

He X. 2000: Effect of Temperature and Photoperiod on Growth, Development and Reproduction of Nysius huttoni White (Hete- roptera: Lygaeidae). MSc Thesis, Massey University, Palmerston North, $108 \mathrm{pp}$.

INGRAM B.R. \& JENNER C.E. 1976: Influence of photoperiod and temperature on developmental time and number of molts in nymphs of two species of Odonata. - Can. J. Zool. 54: 20332045.

IsHIHARA M. 2000: Effect of variation in photoperiodic response on diapause induction and developmental time in the willow leaf beetle, Plagiodera versicolora. - Entomol. Exp. Appl. 96: 27-32.

Jolivet P. 1972: Observations sur les plantes-hôtes de Timarcha du Midi de la France (Col. Chrys.). - Ann. Soc. Hort. Hist. Nat. Hêrault Montpellier 112: 330-332.

Jolivet P. \& PetitPierre E. 1973: Plantes-hôtes connues des Timarcha Latreille (Col. Chrysomelidae). Quelques considérations sur les raisons possibles du trophisme sélectif. - Bull. Soc. Entomol. Fr. 78: 9-24.

Kivelä S.M., Svensson B., Tiwe A. \& Gotthard K. 2015: Thermal plasticity of growth and development varies adaptively among alternative developmental pathways. - Evolution 69: 2399-2413.

Krajicek J., Havlikova M., Bursova M., Ston M., Cabala R., Exnerova A., Stys P. \& Bosakova Z. 2016: Comparative analysis of volatile defensive secretions of three species of Pyrrhocoridae (Insecta: Heteroptera) by gas chromatography-mass spectrometric method. - PLoS ONE 11(12): e0168827, 19 pp.

Kutcherov D.A., Lopatina E.B. \& KipyatKov V.E. 2011: Photoperiod modifies thermal reaction norms for growth and development in the red poplar leaf beetle Chrysomela populi (Coleoptera: Chrysomelidae). - J. Insect Physiol. 57: 892-898.

Kutcherov D., Saulich A., Lopatina E. \& Ryzhrova M. 2015: Stable and variable life-history responses to temperature and photoperiod in the beet webworm, Loxostege sticticalis. - Entomol. Exp. Appl. 154: 228-241.

Kuzovenko A.E., Fayzulin A.I., Kireeva A.S. \& Baltushko A.M. 2015: New data on the distribution of animal species included in the main list and supplement of the Red Data Book of Samara Oblast. - Samarskaya Luka: Probl. Reg. Glob. Ekol. 24: 98-108 [in Russian].

Lopatina E.B., Balashov S.V. \& Kipyatkov V.E. 2007: First demonstration of the influence of photoperiod on the thermal requirements for development in insects and in particular the linden-bug, Pyrrhocoris apterus (Heteroptera: Pyrrhocoridae). - Eur. J. Entomol. 104: 23-31.

Lopatina E.B., Kipyatkov V.E., Balashov S.V. \& Kutcherov D.A. 2011: Photoperiod-temperature interaction-a new form of seasonal control of growth and development in insects and in particular a carabid beetle, Amara communis (Coleoptera: Carabidae). - J. Evol. Biochem. Physiol. 47: 578-592.

Mansfield S., Scholz B., Armitage S. \& Johnson M.-L. 2007: Effects of diet, temperature and photoperiod on development and survival of the bigeyed bug, Geocoris lubra. - BioControl 52: 63-74.

MASAKI S. 1972: Climatic adaptation and photoperiodic response in the band-legged ground cricket. - Evolution 26: 587-600.

Murren C.J., MacLean H.J., Diamond S.E., Steiner U.K., Heskel M.A., Handelsman C.A., Ghalambor C.K., Auld J.R., CallaHAN H.S., Pfennig D.W. ET AL. 2014: Evolutionary change in continuous reaction norms. - Am. Nat. 183: 453-467.

NAKAMURA K. 2003: Effect of photoperiod on development and growth in a pentatomid bug, Dolycoris baccarum. - Entomol. Sci. 6: 11-16.

Nelson R.J., Denlinger D.L. \& Somers D.E. (eds) 2010: Photoperiodism: The Biological Calendar. Oxford University Press, Oxford, NY, xiii +581 pp. 
NoRLING U. 1984: Photoperiodic control of larval development in Leucorrhinia dubia (vander Linden): a comparison between populations from northern and southern Sweden (Anisoptera: Libellulidae). - Odonatologica 13: 529-550.

PAZYUK I.M. \& REZNIK S.Y. 2016: Influence of photoperiod on development and maturation of Macrolophus pygmaeus (Hemiptera, Miridae). - Entomol. Rev. 96: 274-279.

Pluot D. 1978: Données sur Scantius aegyptius, Hémiptère Pyrrhocoride paléarctique, comparaison avec Pyrrhocoris apterus. - Ann. Soc. Entomol. Fr. 14: 703-713.

Puchkov V.G. 1974: Fauna Ukraini. Vol. 21. No. 4. Berytidae, Pyrrhocoridae, Piesmatidae, Aradidae, Tingidae. Naukova Dumka, Kiev, 332 pp. [in Ukrainian].

Saulich A.H., Volkovich T.A. \& Numata H. 1994: Control of seasonal development by photoperiod and temperature in the linden bug, Pyrrhocoris apterus in Belgorod, Russia. - Zool. Sci. 11: 883-887.

SAUNDERS D.S. 1983: A diapause induction-termination asymmetry in the photoperiodic responses of the Linden bug, Pyrrhocoris apterus and an effect of near-critical photoperiods on development. - J. Insect Physiol. 29: 399-405.

SAUNDERS D. 2008: Photoperiodism in insects and other animals. In Björn L.O. (ed.): Photobiology. Springer, New York, pp. 389-416.

Schlichting C. \& Pigliucci M. 1998: Phenotypic Evolution: A Reaction Norm Perspective. Sinauer Associates, Sunderland, MA, $387 \mathrm{pp}$.

ShePARD L.J. \& LuTz P.E. 1976: Larval responses of Plathemis lydia Drury to experimental photoperiods and temperatures (Odonata: Anisoptera). — Am. Midland Nat. 95: 120-130.
SugIKI T. \& MASAKI S. 1972: Photoperiodic control of larval and pupal development in Spilarctia imparilis Butler (Lepidoptera: Arctiidae). - Kontŷu 40: 269-278.

Topp W. \& SMetana A. 1998: Distributional pattern and development of the winter-active beetle Quedius pellax (Staphylinidae). - Glob. Ecol. Biogeogr. 7: 189-195.

Vinogradova E.B. 1960: Experimental investigation of ecological factors inducing imaginal diapause in bloodsucking mosquitoes (Diptera, Culicidae). — Entomol. Obozr. 39: 327-340 [in Russian].

Volkovich T.A. \& Orlova N.A. 1998: Comparative analysis of seasonal development in two species of green lacewings (Neuroptera, Chrysopidae) from the forest-steppe zone of Russia, - Entomol. Rev. 78: 1-12.

WANG S., TAN X.-L., Guo X.-J. \& Zhang F. 2013: Effect of temperature and photoperiod on the development, reproduction, and predation of the predatory ladybird Cheilomenes sexmaculata (Coleoptera: Coccinellidae). - J. Econ. Entomol. 106: 2621-2629.

Zerbino M.S., Altier N.A. \& Panizzi A.R. 2014: Phenological and physiological changes in adult Piezodorus guildinii (Hemiptera: Pentatomidae) due to variation in photoperiod and temperature. - Fla Entomol. 97: 734-743.

Zohdy N.Z.M. \& ABou-Elela R.G. 1975: Effect of photoperiod on the different developmental stages of Spodoptera littoralis (Boisd.) (Lepidoptera: Noctuidae). - Z. Angew. Entomol. 79: $52-56$.

Received March 27, 2018; revised and accepted September 26, 2018 Published online November 5, 2018 